http://dx.doi.org/10.30681/23588403v12i0190104

\title{
ENTRE O HUMANO, O OBJETO E O ABJETO: UM ESTUDO DO INSÓLITO EM “O PIANO", DE ANÍBAL MACHADO, E EM A METAMORFOSE, DE FRANZ KAFKA
}

\author{
Data de recebimento: $21 / 10 / 2018$
}

Aceite: 11/12/2018

\author{
Edilaine ORTIZ (UEMS) ${ }^{1}$ \\ Marcos Vinícius TEIXEIRA (UEMS) ${ }^{2}$
}

\begin{abstract}
RESUMO: A crítica literária, ao abordar o universo ficcional de Aníbal Monteiro Machado (18941964), de forma pontual em boa medida, tem apontado para uma presença ou herança relacionada ao universo de Franz Kafka (1883-1924). Na obra do escritor mineiro, nesse sentido, ganha relevância o conto "O piano", publicado pela primeira vez em livro em 1944. O propósito deste estudo é realizar uma análise comparativa entre o conto "O piano", de Aníbal Machado, e a novela A metamorfose, de Franz Kafka, levando-se em consideração os personagens o piano e Gregor Samsa e o tratamento que recebem ao longo das narrativas. De um lado temos um velho piano humanizado e elevado à condição superior, semelhante a um parente, e de outro, um ser humano metamorfoseado em estranho inseto, apartado do seio familiar ainda que se mantenha na própria casa. Espera-se, assim, contribuir para a investigação da obra do escritor brasileiro, que possui o insólito como uma característica recorrente, além de refletir sobre a novela de Kafka.
\end{abstract}

Palavras-chave: Aníbal Machado. Franz Kafka. O piano. A metamorfose.

ABSTRACT: When approaching the fictional universe of Aníbal Monteiro Machado (1894-1964), literary studies have - duly and in good measure - pointed out to a presence or inheritance from the universe of Franz Kafka (1883-1924). Accordingly, the work of the writer from Minas Gerais, particularly the short story "The Piano" - first published in a book in 1944 - gains relevance. This study aims to provide a comparative analysis between the short story "The Piano", by Aníbal Machado and the novella The Metamorphosis, by Franz Kafka considering both characters, that are The Piano and Gregor Samsa, and how they are treated throughout the stories. On one side, there is an old humanized piano, elevated to a superior condition, similar to that of a relative, and on the other there is a human-being metamorphosed into a bizarre bug, estranged from his own family although remaining in their own house. The intent is to contribute to the investigation of this Brazilian writer's work, who has the unusual as a recurring trait, and to reflect on Kafka's novella.

Keywords: Aníbal Machado; Franz Kafka; The Piano; The Metamorphosis.

\section{INTRODUÇÃO}

Em A metamorfose, encontramos o absurdo, a esperança, o suspense e a tragédia de forma que a pluralidade de concepções e interpretações permitem reflexões sobre o insólito. Em geral, as obras e a singularidade do universo literário de Kafka fizeram-no um autor

\footnotetext{
${ }^{1}$ Graduanda do Curso de Letras da Universidade Estadual de Mato Grosso do Sul, Jardim-MS, Brasil. Membro do grupo de pesquisa Modernismo periférico: poéticas do século XX. E-mail: edilaineortiz@ @otmail.com

${ }^{2}$ Doutor em Literatura Brasileira pela USP. Professor do curso de Letras da Universidade Estadual de Mato Grosso do Sul, Campo Grande-MS. Brasil. Líder do grupo de pesquisa Modernismo periférico: poéticas do século XX. E-mail: marcosteixeira@uems.br
} 
influente e de extrema importância para a literatura universal. No Brasil, Kafka influenciou inúmeros escritores, dentre os quais o contista e ensaísta Aníbal Monteiro Machado que é conhecido por sua qualidade estética e pela presença do Surrealismo em suas obras. Aníbal também chegou a traduzir peças teatrais importantes, dentre elas, O Guardião do Túmulo, de Franz Kafka, juntamente com o diretor teatral Willy Keller, durante o século XX. Neste estudo, pretende-se realizar uma análise comparativa entre o conto "O piano", de Aníbal Monteiro Machado (1894-1964), e a novela A metamorfose, de Franz Kafka (1883-1924), levando-se em consideração os personagens o piano e Gregor Samsa. O tratamento que o instrumento personificado de "O piano" recebe, isto é, a atribuição de características humanas ao móvel, pode ser relacionado e comparado ao protagonista da obra de Kafka, que, por sua vez, passa da condição humana à de estranha criatura. Também nos interessa a abordagem do contexto familiar e o universo dos protagonistas.

As narrativas de Aníbal Machado fazem analogias com a contemporaneidade da vida cotidiana, por meio de uma escrita clara e objetiva. $\mathrm{O}$ autor trata seus personagens, dando-lhes vida e corporificação, unindo realidade e fantasia, conforme observou M. Cavalcanti Proença em "Os balões cativos": "A narrativa de Aníbal Machado se desenvolve em terreno fronteiriço, ora pisando chão de realidade, ora pairando nas nuvens do imaginário, entre sonho e vigília, entre espírito e matéria, verdade e mentira, relatório e ficção" (PROENÇA, 1997, p.16).

Outra característica de Aníbal é o adiamento de uma possível solução para a problemática do enredo, que inicialmente parece apontar para um desfecho simples e fácil, mas ao longo da narrativa torna-se complexo. São nesses momentos que o autor proporciona certo suspense ao leitor e pode-se dizer que o prepara para o próximo acontecimento. Quando não ocorre conforme o esperado, surge a dúvida e a especulação. Assim como em outras obras de Aníbal, algo está sempre em construção. É o que Marcos Teixeira investigou em sua tese Aníbal Machado: Um escritor em preparativos, de 2011:

No universo de Aníbal Machado, o sujeito se caracteriza como um homem sempre em preparativos. Daí o entendimento da vida como algo provisório, a expectativa de que algo importante, grandioso ou definitivo ocorrerá, ou a sensação tardia de que a vida foi uma longa espera pelo incerto. (TEIXEIRA, 2011, p.10).

Em “O piano” é possível perceber essa característica de espera pelo incerto, pois uma expectativa é criada na história; é como se o leitor esperasse por algo que não é lhe dado ao 
final da história. O tratamento dado pelo autor à narrativa, nesse sentido, é irônico e a história se aproxima muito de uma situação kafkiana. O que Aníbal oferece ao seu leitor ao final do conto é uma história indefinida, insólita, que não se define e faz com que seja preciso que este retorne à história várias vezes para então descobrir que de nada adiantou toda especulação, possivelmente elaborada, para dirimir a angústia que se criara ao lidar com um piano importante.

Nota-se, no conto "O piano", característica que também pode ser observada em outras histórias como em "O telegrama de Ataxerxes", que Aníbal trabalha com situações aparentemente comuns, de forma que o leitor, ao se deparar com o insustentável na narrativa, questiona-se sobre em qual ponto a situação comum tornou-se tão complexa. Essa característica é também encontrada em Franz Kafka não somente em A Metamorfose, mas em outras obras como O Processo (1914) e O Castelo (1922), ambas com problemáticas insólitas. Daí o termo kafkiano ser utilizado para caracterizar outros universos literários, ressaltando, por exemplo, uma situação incompreensível: "O adjetivo kafkiano tornou-se para nós sinônimo de incompreensível, caracterizando em geral uma sequência de fatos aparentemente banais e, ao mesmo tempo refratários a qualquer tipo de explicação.” (CARONE, 1997, n. p.). Pode-se dizer que a narrativa de Kafka consiste em unir uma situação banal a um excesso de lógica que intimida o leitor, conforme ressalta Albert Camus:

Conhece-se a história do louco que pescava numa banheira: um médico que tinha suas ideias sobre os tratamentos psiquiátricos lhe perguntava "se isso mordia" e recebeu a resposta rigorosa: "Mas claro que não, seu imbecil, pois se é uma banheira". Essa história é do gênero barroco. Mas se capta aí, de maneira sensível, como o efeito absurdo está ligado a um excesso de lógica. O mundo de Kafka, na verdade, é um universo inexprimível em que o homem se dá ao luxo supliciante de pescar em uma banheira sabendo que nada sairá dali. (CAMUS, 1989, p.154).

Conforme Camus é possível perceber a característica kafkiana do autor de $A$ metamorfose ao inserir o elemento insólito em sua obra através do absurdo e do excesso de lógica. Nesse sentido, pode-se afirmar que o que ocorre com o conto "O piano" de Aníbal se assemelha também a uma situação kafkiana, pois trata-se de uma situação banal que se desenrola de forma absurda e que se torna lógica.

\section{2 “O PIANO” E A METAMORFOSE: UM ESTUDO COMPARATIVO}


Em “O piano", de Aníbal Machado, podemos observar uma sequência de acontecimentos que nos possibilita relacionar o seu enredo à obra $A$ metamorfose, de Kakfa. Dentre eles, é possível destacar a questão familiar e o contexto das personagens protagonistas Gregor Samsa e o piano. Além das semelhanças entre as histórias, há também diferenças que se estabelecem como espelhamento e o que temos ao final de ambas é a instauração do insólito que podemos classificar como kafkiano.

Em A metamorfose, o pai de Gregor é forte, mas negligente; preocupa-se com o filho enquanto ser humano e provedor do lar, mas envergonha-se quando o vê transformado em um inseto asqueiroso e incapaz de retomar suas funções. Nessa perspectiva, pode-se afirmar que Kafka, assim como se verá em Aníbal, traz em sua narrativa elementos que, no universo da ficção, atribuem ambiguidade ao personagem. Essa dualidade foi apontada por Albert Camus do seguinte modo:

A metamorfose, por sua vez, representa certamente a terrível iconografia de uma ética da lucidez. Mas é também o produto desse assombro inimaginável que experimenta o homem ao sentir o bicho que ele, sem esforço, se tornou. É nessa ambiguidade fundamental que está o segredo de Kafka. Essas perpétuas oscilações entre o natural e o extraordinário, o indivíduo e o universal, o trágico e o cotidiano, o absurdo e o lógico reaparecem na sua obra inteira e lhe dão ao mesmo tempo sua ressonância e significado. São esses paradoxos que é preciso enumerar, são essas contradições que é preciso ressaltar, para compreender a obra absurda. (CAMUS, 1989, p.151).

Kafka é objetivo em sua trama, simplesmente constrói uma obra em que o impossível é possível, conforme observado por Tzvetan Todorov sobre a literatura fantástica: "A literatura só se torna possível na medida em que se torna impossível” (TODOROV, 1992, p. 183). É justamente esse fato que faz do texto de Kafka um texto literário eficiente e verossímil na medida em que é narrado. O autor relata o absurdo de forma natural. Modesto Carone afirma que "[...] o absurdo é narrado num tom preciso, frio, formal, como se o pesadelo integrasse naturalmente o cotidiano: a dor dos escritos de Kafka deve muito a essa técnica da indiferença." (CARONE, 1997, n. p.). O final dessa história não nos deixa duvidar de que tal acontecimento tem algo a mais a nos dizer e que vai muito além do questionamento do que é o real no universo da ficção.

Considerando a abordagem da literatura fantástica em sua teoria, retomamos as ideias de Todorov para identificar as características que categorizam o fantástico em $A$ metamorfose, considerada por este como a obra mais célebre desse universo literário, 
principalmente pela maneira inovadora com que Kafka constrói o fantástico, visto que o autor acabou seguindo por um caminho nunca antes experimentado nesse gênero:

Se abordarmos esta narrativa com as categorias anteriormente elaboradas, vemos que ela se distingue fortemente das histórias fantásticas tradicionais. Em primeiro lugar, o acontecimento estranho não aparece depois de uma série de indicações indiretas, como o ponto mais alto de uma gradação: ele está contido em toda primeira frase. A narrativa fantástica partia de uma situação perfeitamente natural para alcançar o sobrenatural, 'A Metamorfose' parte do acontecimento sobrenatural para dar-lhe, no curso da narrativa, uma aparência cada vez mais natural; e o final da história é o mais distante possível do sobrenatural. Qualquer hesitação torna-se de imediato inútil: ela servia para preparar a percepção do acontecimento inaudito, caracterizava a passagem do natural ao sobrenatural. [...] (TODOROV, 1992, p. 179).

Kafka surpreende ao iniciar a narrativa com o acontecimento incomum logo na primeira frase: "Quando certa manhã Gregor Samsa acordou de sonhos intranquilos, encontrou-se em sua cama metamorfoseado num inseto monstruoso.” (KAFKA, 1997, p. 7). A trama é engendrada de forma verossímil, mesmo abrangendo um acontecimento incomum. Gregor ter se transformado em um inseto torna-se possível. No entanto, o leitor não descarta a possibilidade de uma explicação e não perde a esperança de que a qualquer momento Gregor possa acordar e ver que tudo não passou de um sonho. A metamorfose seria então uma metáfora utilizada pelo autor com o intuito de moralizar o problema da negligência familiar. A própria palavra metamorfose sugere uma transformação, do homem ao animal, ou talvez do homem a sujeito incapaz de retomar suas atividades humanas. Essas possibilidades de leitura, se coerentes com o texto, permitem a análise da obra sobre vários pontos de vista que de certa forma trazem humanidade ao leitor, conforme conceituou Antonio Candido na palestra "O direito à literatura", na qual afirma: "Ela não corrompe nem edifica, portanto; mas, trazendo livremente em si o que chamamos bem e o que chamamos o mal, humaniza em sentido profundo, porque faz viver." (CANDIDO, 2011, p. 178).

A narrativa inicia-se em um cenário comum, no qual o personagem principal, Gregor Samsa é também o provedor do lar. A família de Gregor é completamente dependente de seu emprego de caixeiro-viajante, ele, por consciência de seu importante papel e preocupado com as dívidas da família, suporta a rotina cansativa de trabalho. No entanto, é evidente na narrativa que o personagem só permanece em seu emprego por causa da família, conforme se observa no seguinte trecho: “[...] Se não me contivesse, por causa dos meus pais, teria pedido demissão há muito tempo; teria me postado diante do chefe e dito o que penso do fundo do coração. [...]" (KAFKA, 1997, p. 9). 
Após o confronto entre a família e o personagem metamorfoseado, é narrada a adaptação de Gregor à condição de inseto: a dificuldade em se alimentar, se locomover, e em compreender o novo corpo. Nos primeiros dias, a irmã de Gregor mostra-se comovida e decide ajudar o irmão trazendo-lhe comida e limpando seu quarto esporadicamente. Gregor, no entanto, reconhece o quanto ele pode ser assustador para a família devido à sua aparência grotesca e, por isso, esconde-se toda vez que percebe a presença de alguém no quarto.

Os momentos de adaptação tornam-se ainda mais dolorosos para Gregor na medida em que o personagem é esquecido pela família. Até mesmo a irmã, que antes o ajudava, o abandona definitivamente. Nesse ponto, percebe-se que os pais o suportam movidos por uma espécie de obrigação familiar, o que os torna cada vez mais negligentes, principalmente pela repugnância explícita do pai.

Em determinado momento, Gregor é esquecido e sua existência torna-se insignificante para a família. Em seguida, passa a viver em seu quarto que é transformado em depósito, e com pouquíssimo espaço para se locomover. O personagem vai definhando aos poucos até que ocorre o momento de sua morte.

Quando a família Samsa se dá conta da morte de Gregor, ainda que demonstrem certa tristeza no início, o sentimento que se sobressai é o de alívio. E a maior preocupação da família, a partir disso, passa a ser o futuro da filha, “[...] pensaram que já era tempo de procurar um bom marido para ela. E pareceu-lhes como que uma confirmação dos seus novos sonhos e boas intenções [...]" (KAFKA, 1997, p. 85).

A ideia de casamento da filha é algo que agora faz parte dos planos da família Samsa e a morte de Gregor é vista como uma solução e uma espécie de aval para que os novos planos pudessem acontecer, pois não há o sentimento de remorso expectado pela trama, apenas um semblante melancólico e esboços de movimentos que não são concretizados: “-É o que estou tentando dizer - disse a faxineira e para provar empurrou o cadáver de Gregor com a vassoura mais um longo trecho para o lado." (KAFKA, 1997, p.79). Nesse momento, "a senhora Samsa esboçou um movimento, como se quisesse deter a vasoura, mas não o fez. — Bem. - disse o senhor Samsa —, agora podemos agradecer a Deus". (KAFKA, 1997, p. 80).

É evidente que a literatura se relaciona e dialoga frequentemente. É possível observarmos, nesse sentido, uma influência de Kafka em Aníbal, especialmente em "O piano". Porém, em nossa pesquisa, encontramos poucas referências a essa influência, a maior parte do que encontramos se resume em sugestões muito vagas ou pontuais relacionando, por 
exemplo, as preferências literárias de Aníbal, conforme consta no livro Escritores Brasileiros Contemporâneos de Renard Perez: “Aníbal Machado não tem admirações exclusivistas. Mas entre suas preferências literárias cita Gide, Kafka, Proust, os poetas românticos alemães, os romancistas ingleses e russos e alguns supra-realistas franceses. [...]” (PEREZ, 1960, p. 25).

Uma relação interessante foi apontada por Márcia Azevedo Coelho em sua tese: Entre a Pedra e o Vento: uma análise dos contos de Aníbal Machado (2009). No estudo de Márcia encontramos uma proposta de relação direta entre o conto "O Homem Alto" de Aníbal com A metamorfose de Kakfa, especificamente com Gregor Samsa. Márcia entende que a metamorfose de Gregor é uma metáfora da fuga da realidade. Para a pesquisadora, a metamorfose teria sido uma alternativa encontrada por Gregor para se livrar das amarras sociais que o prendiam a uma vida sufocante, essa interpretação é associada ao protagonista de "O Homem alto" no momento em que o protagonista procura se ausentar da realidade sonhando em se tornar um homem de maior estatura, conforme o fragmento a seguir:

O sonho recorrente faz com que ocorra uma estranha metamorfose no protagonista. A associação da passagem com o conto metamorfose de Kafka é imediata, ainda que a conseqüência siga em direção inversa, já que na novela do escritor austríaco, Gregor Samsa transforma-se para "fugir" da carga social imposta a ele, ao passo que em "O Homem Alto", o protagonista metamorfoseia-se para suportar a carga e se adequar melhor socialmente, apesar disso, a crítica de ambas as obras dirige-se à estrutura alienante típica das sociedades modernas. (COELHO, 2009, p. 82-83).

Vale lembrar que a interpretação de Márcia nos afasta da ideia do Fantástico, observado por Todorov sobre a literatura fantástica presente na obra A metamorfose, visto que, a partir da interpretação da pesquisadora, afirmamos a possibilidade da metáfora, ou seja, o protagonista não está mais no campo do fantástico e se aproxima mais do universo do estranho, pois, de acordo com Todorov, neste campo, consideramos a metáfora, mas admitimos que ela ainda será esclarecida dentro de um universo possível na ficção. Em nosso estudo, nos limitamos ao campo do fantástico, que se encontra entre o estranho e o maravilhoso.

Outro autor a abordar esta relação é Mario Pontes, ainda que tenha feito de forma breve. Trata-se do texto "O iniciado do movimento", escrito para a décima edição de João Ternura, em 2004. Pontes não deixa claro sobre qual narrativa de Kafka está se referindo. Nota-se que se trata de uma visão geral da narrativa kafkiana relacionada ao conto "O piano":

Não é difícil perceber na obra de Aníbal Machado a presença - sempre discreta - de autores e ideias que marcaram seu século. O desenvolvimento 
de histórias como "O piano" e "O telegrama de Ataxerxes" deixa pouca dúvida de que elas tenham sido roçadas pela asa denunciadora de Kafka. Com elas somos advertidos, primeiro, de que qualquer circunstância da vida moderna pode repentinamente nos tornar presas do absurdo, e segundo, de que em nosso tempo, mais do que nunca, o poder tornou-se distante e ilusório, mas também perigoso e desapiedado. (PONTES, 2004, p. 09).

O absurdo que Pontes observa em Aníbal é consequência de uma série de sugestões que propiciam a dúvida e a ambiguidade na narrativa. Em "O piano", em determinados momentos o narrador cria certo suspense quanto à identidade do móvel, quanto ao conflito com a relutância da família em se desfazer do piano e à particularidade dos personagens com a ideia do sacrifício. M. Cavalcanti Proença conceituou o caso do piano como polissêmico: "No caso do piano, há uma polissemia: para Oliveira, ele representa um parente, para a moça noiva, a cama de casal; nem para Rosália, a realista, continua um piano, pois para ela, é dinheiro, apenas dinheiro". (PROENÇA, 1997, p. 18).

A formação familiar do conto tem nítida semelhança com a de A metamorfose, sendo sucessivamente: pai, mãe, irmã e o irreal piano ou o grotesco inseto. Tais comparações sugerem a releitura do conto sob o ponto de vista analítico e comparativo, considerando a presença do insólito no universo literário de Aníbal Machado.

Enquanto a negligência se sobressai no contexto familiar de Kafka, na narrativa de "O piano" temos João de Oliveira exercendo um papel muito semelhante ao de um pai ou parente próximo em relação à figura humanizada do piano, Rosália a mãe preocupada e ao mesmo tempo interessada no futuro da filha, e a filha que age com certo egoísmo e que muda de ideia conforme seus interesses.

Aníbal Machado, nesse sentido, conseguiu encontrar na literatura uma posição de equilíbrio, pois consegue criar sutilmente um universo insólito na história. A narrativa do autor começa de forma simples, sempre contendo situações cotidianas, das quais não se espera um desenrolar tão complexo. Em sua narrativa, ele escreve pontualmente, utilizando uma linguagem clara e ao mesmo tempo sugestiva e ambígua. Algo que lhe é muito peculiar, pois através de sua clareza, conduz o leitor por um caminho aparentemente previsível, simples, já articulado, mas que de repente toma um rumo inesperado ao final da história.

A história de "O piano" gira em torno de um móvel que significa muito para a família Oliveira, principalmente para João de Oliveira que insiste em atribuir características humanas ao piano e em preservar as lembranças que o móvel evoca. Há uma série de suposições que se pode fazer acerca da narrativa, que começa de forma sutil, com um simples 
diálogo sobre a venda de um piano. O que ocorre a seguir torna-se quase impossível de explicar, é insólito, ou como escreveu M. Cavalcanti Proença: "só nos ocorrem adjetivos: indizível, intraduzível.” (PROENÇA, 1989, p. xv).

Em vários momentos, percebe-se que João de Oliveira se refere ao piano como a alguém de sua família, um sujeito velho e guardião de muitas memórias. A esposa Rosália, no início do conto, parece compadecer-se da situação do piano, mas ao lembrar-se do casamento da filha e do espaço que será liberado após a venda do móvel, bem como o dinheiro, muda seu posicionamento friamente, pois era preciso "custear o enxoval de Sara com a venda; transformar a saleta em quarto para futuro casal, - teriam que dispor dele de qualquer maneira." (MACHADO, 1959, p.229). A filha Sara, em certo momento da narrativa, afirma que se contentaria com pouco enxoval e que não tinha necessidade de se livrarem do piano, mas a mãe a faz escolher entre marido e piano. Sara escolhe o marido, e passa a enxergar o piano como um empecilho para seu casamento. Enquanto isso, João de Oliveira "Já não fazia questão do preço. Queria apenas que seu piano fosse tratado com certa atenção. Ao menos isso. Podia não valer muito dinheiro, mas merecia consideração especial.” (MACHADO, 1959, p.233).

Em seu universo literário, Aníbal trabalha com muitas ambiguidades. Em "O piano", os personagens assumem características que acabam se transformando ao longo da narrativa. João de Oliveira, por exemplo, sofre ao tentar encontrar um lugar para o piano ao mesmo tempo em que lida com a ideia de desapego pelo móvel. Em determinados momentos, o personagem assume uma postura fria como que tomando a iniciativa mais racional por se tratar de um móvel, mas essa postura aparentemente racional se aproxima muito de uma situação na qual o sujeito se encontra em uma espécie transe ou insanidade, algo que é recorrente em pessoas que estão passando pelo momento da perda de algum parente próximo, por exemplo.

O papel do pai nas narrativas pode ser analisado levando em consideração aspectos que são construídos a partir da narrativa ambígua que sugere a figura paterna, principalmente na história de "O piano". Primeiro é preciso que compreendamos João de Oliveira como um pai, e dessa forma, é possível compreender o sentimento de preocupação e remorso do personagem ao lidar com a perda do piano. Diferente do pai negligente de Gregor em $A$ metamorfose, João de Oliveira faz o papel de pai preocupado e quando percebe que não há mais alternativas para o piano, decide jogá-lo ao mar em uma atitude desesperadora, como que para libertar o móvel. Em seguida chora, lembra-se do piano com remorso e tristeza. Ter 
jogado o instrumento, torna-se então, uma saída para João, e o fim do piano é tido como a morte de um familiar que estaria descansando livremente do cotidiano da vida, conforme se observa no seguinte fragmento:

[...] Estava longe agora, viajando milhas... Longe... A caminho dos mares do Sul... E livre. Mais que ele [João], que Sara, que Rosália. Quem se sentia abandonado agora era ele, João de Oliveira. Ele e sua família. O piano, não. Partira para aventura. Mudara de ambiente. De caráter, com certeza... Antes, era de casa, só para a família. Agora, já não é mais seu piano. Uma coisa solta no mundo. Cheia de vida, de orgulho... Que se move debaixo dos mares. Que ressoa... Que é abraçada por todas as águas e pode ir para qualquer direção. (MACHADO, 1959, p.250).

No momento da morte do personagem Gregor Samsa e do fim do piano, há uma oposição entre os enredos. Enquanto na narrativa de Aníbal, mãe e filha oscilam entre sentimento de desapego e remorso pelo piano, na narrativa de Kafka mãe e filha demonstram certa preocupação no início, mas logo passam a rejeitá-lo gradativamente e a preocupação que tiveram antes é atribuída a características materiais como o dinheiro que provinha do emprego de Gregor. Neste caso, a humanidade que poderia haver em relação ao personagem não significa mais nada para elas, diferente da família Oliveira que atribui humanidade ao piano o tempo todo.

Na narrativa kafkiana Gregor Samsa sofre uma metamorfose, já em "O piano”, podese dizer que os personagens do conto é que se metamorfoseiam em suas vontades e ideias. No início, Rosália e Sara, sofrem ao lidar com a ideia de o piano sair da família, mas mudam de opinião logo em seguida, sendo João de Oliveira o único que ainda insiste em procurar alternativas para o móvel. Já no momento em que João decide atirar o piano ao mar, seu aspecto muda e ele passa a agir com certa frieza em relação ao móvel, enquanto a esposa e a filha se tornam mais sentimentais. Há, portanto, uma oscilação de sentimentos que corrobora o aspecto da ambiguidade e do insólito na narrativa do conto.

A presença do insólito, que encontramos no contexto familiar da novela de Kafka também pode ser percebida no contexto familiar da narrativa de Aníbal. É nessa perspectiva que os personagens protagonistas são identificados: de um lado temos um ser humano metamorfoseado, do outro, um velho piano humanizado.

A semelhança no núcleo familiar em ambas as histórias, como dissemos, são muito próximas, pois as famílias possuem exatamente os mesmos componentes, se levarmos em consideração o piano e Gregor Samsa como elementos alegóricos nas tramas. Na novela de 
Kafka, em um diálogo com a família, a irmã de Gregor nega a presença do irmão metamorfoseado e rompe com a ideia de obrigação familiar que havia se estabelecido entre eles. A partir desse posicionamento é possível afirmar que a moça faz questão de se livrar de Gregor, conforme o seguinte fragmento:

[...] assim não pode continuar. Se vocês acaso não compreendem, eu compreendo. Não quero pronunciar o nome do meu irmão diante desse monstro e por isso digo apenas o seguinte: precisamos tentar nos livrar dele. [...] (KAFKA, 1997, p. 74).

A negação da filha de A metamorfose é algo que também ocorre em "O piano", pois "toda vez que o olhar de Sarita pousava sobre o piano, transformava-o em cama de casal em que ela se via abraçada ao seu tenente de artilharia." (MACHADO, 1959, p.235). E de sentimento de apego a um móvel que teria sido tão importante para a família, no início do conto, a filha de João de Oliveira passa a ver o piano como um objeto incômodo:

"Eu quero que ele saia o quanto antes, mamãe". Faltam poucos dias e meu quarto nem está arranjado ainda! Não vejo nada para o casamento. Só esse piano enjoado para atrapalhar a minha vida, esse piano que ninguém quer... (MACHADO, 1959, p.237).

O casamento da moça da família está presente nas duas histórias. Após a morte de Gregor, em A metamorfose, seus pais preocupam-se com o casamento da filha e agem como se tivessem se livrado de algo que estaria impedindo esses novos planos. Na família de João, por outro lado, é justamente pelo casamento da filha que é preciso desfazer-se do piano, por esse motivo é necessário que o piano seja sacrificado:

[...] A questão, prosseguia Rosália, é que esta casa é uma caixa de fósforos. Onde iremos alojar o casal? Teremos que sacrificar o piano de qualquer maneira para dar espaço. Nossa Senhora! Todo mundo hoje quer espaço, precisa de espaço!... (MACHADO, 1959, p. 232).

A questão do espaço ocupado pelo piano é um dos motivos pelos quais a família Oliveira precisa se livrar do piano. Essa preocupação também ocorre na família Samsa, mas, ao contrário dos Oliveiras, eles buscam um lugar menor, que ocupe menos espaço, e após o claro sentimento de alívio ao ver que Gregor se fora para sempre, eles conversam sobre um novo apartamento e os novos planos para o casamento da filha, no fragmento a seguir podemos observar a preocupação com o espaço e com o casamento, já mencionado anteriormente: 
Recostados com conforto nos seus bancos, conversaram sobre as perspectivas do futuro, descobrindo que, examinadas de perto, elas não eram de modo algum más, pois os três tinham empregos muito vantajosos e promissores - sobre os quais, na verdade, nunca tinham feito perguntas pormenorizadas um ao outro. É claro que a grande melhora imediata de casa; eles agora queriam um apartamento menor e mais barato, mas mais bem situado e sobretudo mais prático do que o atual, que tinha sido escolhido ainda por Gregor. Enquanto conversavam assim, ocorreu ao senhor e à senhora Samsa, quase que simultaneamente, à vista da filha cada vez mais animada, que ela - apesar da canseira dos últimos tempos, que empalidecera suas faces - havia florescido em uma jovem bonita e opulenta. Cada vez mais silenciosos e se entendendo quase inconscientemente através de olhares, pensaram que já era tempo de procurar um bom marido para ela. [...] (KAFKA, 1997, p. 84-85).

Conforme se nota no fragmento acima, a família Samsa está aliviada e esperançosa por um futuro melhor que projeta a partir da ideia de casamento, que poderá surgir ao olharem para a filha e perceberem que já era tempo, e também pela ideia de procurar um lugar melhor que correspondesse às suas expectativas de futuro promissor. Vimos, portanto, que na família Oliveira há um dilema por conta do espaço ocupado pelo piano, pois estaria atrapalhando o quarto do futuro casal, já na família Samsa o espaço em que viviam era grande demais e também mais caro, além disso, havia a lembrança de Gregor, principalmente porque fora ele quem havia escolhido o apartamento.

Nesse momento há uma oposição de sentimentos entre as famílias, provocando algo semelhante ao reflexo de um espelho, pois na família Samsa o que prevalece é o sentimento de alívio que ocorre logo após a comprovação da morte de Gregor, quando eles entram no quarto e fazem o "sinal da cruz" em agradecimento a Deus. Já em "O piano", o sentimento que se sobressai é o de remorso que ocorre logo após o móvel ter sido engolido pelo oceano e João de Oliveira age como se estivesse enlutado, o que definitivamente não ocorre em $A$ metamorfose. Desse modo, os sentimentos estariam invertidos, pois o alívio deveria pertencer a João de Oliveira, já que aparentemente trata-se da perda de um móvel, enquanto que o remorso poderia estar na família Samsa que perdera um membro da família.

Nos momentos finais de ambas as tramas, há muita hesitação, e cria-se expectativa para um deus ex machina, que poderia solucionar o problema do piano e de Gregor. No entanto, toda expectativa é transformada em frustração e transmite uma sensação de vazio, o que caracteriza o insólito nas duas histórias. No final de ambas chega-se à conclusão de que todo esforço e sofrimento de nada valeram, pois revela um desfecho trágico e absurdo. E não houve recompensa para tal, é como se o fim nada tivesse a ver com a narrativa anterior. As histórias permanecem ambíguas. Há um sentimento de insatisfação que se dá pelo desejo de 
se encontrar outro fim, que, por sua vez, fosse satisfatório. Como não há, a narrativa permanece inacabada, como se o final fizesse parte de outra história, mas é justamente nessa espécie de espelho que reflete efeitos contrários, que se encontra o ponto final da narrativa anibalina e da kafkiana.

\section{CONSIDERAÇÕES FINAIS}

O propósito deste trabalho foi apresentar a relação comparativa entre o conto " $\mathrm{O}$ piano" de Aníbal Machado e A metamorfose de Franz Kafka. Apresentamos os pontos que unem as narrativas e também os pontos que as diferenciam e estabelecemos uma relação que as aproxima, partindo do princípio de que a literatura se relaciona e dialoga frequentemente. Em nossa pesquisa, encontramos diversos materiais que contribuíram para a compreensão da narrativa kafkiana e da anibalina, porém, no que diz respeito à relação comparativa específica entre as obras, encontramos apenas apontamentos da crítica muito abrangentes, o que justifica o propósito deste trabalho.

Assim como ocorre em "O piano", a questão que aqui estudamos está presente em várias outras histórias de Aníbal Machado como em "O telegrama de Ataxerxes; "O Homem e seu capote"; "Viagem aos seios de Duília"; "O iniciado do Vento" e João Ternura. Em "O telegrama de Ataxerxes", por exemplo, temos a insólita situação de um sujeito que sonha em mudar de vida através da suposta amizade com o presidente da nação. No desenrolar da história, o narrador constrói uma espécie de teia de acontecimentos que parecem estar se direcionando pelo caminho mais óbvio possível, mas o que ocorre ao final da história, após todo esforço da protagonista, é a insólita dúvida deixada pelo narrador, pois não há um ponto que determine o final da história. Há uma espécie de lacuna, pois, não se sabe se o telegrama de Ataxerxes foi enviado ou não e é esse o desfecho da história. É como se a história precisasse ser finalizada com algum esclarecimento final, mas isso não ocorre. Essa é uma característica intrigante em Aníbal Machado. O leitor das histórias de Aníbal procura encontrar respostas que podem ter passado despercebidas na leitura. O intrigante é que a escrita clara do autor, à primeira vista, não nos remete a algo tão inesperado como o que ocorre nesses momentos. Até mesmo as pontuações utilizadas pelo autor se tornam pistas valiosas para quem deseja compreender a insólita e quase sempre misteriosa obra anibalina.

O insólito kafkiano também pode ser observado em relação ao personagem João Ternura no conto “O Homem e seu Capote”, publicado como apêndice de seu único romance. 
Nessa história, temos uma narrativa muito semelhante ao conto "O piano", inclusive, sabemos disso, através da declaração da editora José Olympio à primeira edição do romance João Ternura:

De acordo ainda com a família de Aníbal M. Machado, acrescentou-se a esta edição, em apêndice, o texto publicado pela Revista Acadêmica, do Rio de Janeiro, em seu número 51, de setembro de 1940, como conto, sob o título "O Homem e seu capote", e que constitui evidentemente um capítulo de João Ternura, não aproveitado pelo autor na versão definitiva do romance possivelmente pelo aproveitamento do tema no conto "O piano" e aqui incluído por sugestão de Carlos Drummond de Andrade e M. Cavalcanti Proença, que consideram boas as páginas desse capítulo esquecido. (MACHADO, 1965, p. x).

Nota-se que Aníbal aproveitou o tema do capote em "O piano" e, percebe-se como uma dimensão kafkiana está presente ou foi utilizada pelo autor também nessa história. Essa característica é notada justamente no desfecho da narrativa, na qual o protagonista é acusado por roubo de seu próprio capote, ao mesmo tempo em que tenta se livrar dele, ou seja, a personagem se torna vítima de seu próprio objeto, de modo simultâneo, o capote é indesejado, mas também necessário. É nessa ambivalência que se encontra o final das histórias inacabadas de Aníbal. No momento em que a situação finalmente parece ter sido resolvida surge algo inesperado: Ternura é acusado por roubo de seu próprio capote, pois era inimaginável um sujeito como ele, possuir um casaco tão imponente como aquele.

Ao investigarmos a relação entre A metamorfose e "O piano", procuramos explorar a dimensão kafkiana, que está presente em boa parte da obra de Aníbal Machado no sentido em que pontuamos, no conto em que talvez esteja melhor realizada. Ao realizarmos este estudo, procurou-se contribuir para a compreensão da literatura deste escritor, que vem recebendo maior atenção da crítica nos últimos anos em contraste com o fato de ainda ser pouco mencionado nos livros que têm como propósito historiar a nossa literatura. Ao mesmo tempo entendemos que a comparação com a famosa novela de Kafka contribui para manter viva a sua importância, estabelecendo uma relação que consideramos relevante para os estudos literários.

\section{REFERÊNCIAS}


CAMUS, Albert. A esperança e o absurdo na obra de Franz Kafka. In: O Mito de Sísifo. Tradução de Mauro Gama. Rio de Janeiro: Guanabara, 1989, p. 149-162.

CANDIDO, Antonio. O direito à literatura. In: Vários escritos. 5. ed. Rio de Janeiro: ouro sobre azul, 2011, p. 171-193.

COELho, Márcia Azevedo. Entre a Pedra e o Vento: uma análise dos contos de Aníbal Machado. 2009. Tese (Doutorado em Literatura Brasileira) - Universidade de São Paulo, São Paulo, 2009.

KAFKA, Franz. A metamorfose. Tradução de Modesto Carone. 5. ed. São Paulo: Companhia das Letras, 1997.

KAFKA, Franz. O Castelo. Tradução de Modesto Carone. São Paulo: Companhia das Letras, 2000.

KAFKA, Franz. O Processo. Tradução de Modesto Carone. São Paulo: Companhia das Letras, 1998.

MACHADO, Aníbal. João Ternura. Rio de Janeiro: José Olympio, 1965.

MACHADO, Aníbal. Histórias Reunidas. Rio de Janeiro: José Olympio, 1959.

PEREZ, Renard. Escritores Brasileiros Contemporâneos. Rio de Janeiro: Civilização Brasileira, 1960, p.19-26.

PONTES, Mario. O iniciado do movimento. In: MACHADO, Aníbal. João Ternura. 10. ed. Rio de Janeiro: José Olympio, 2004, p. 7-13.

PROENÇA, M Cavalcanti. Os Balões Cativos. In: MACHADO, Aníbal. A Morte da portaestandarte, Tati, a Garota e outras histórias. 15. ed. Rio de Janeiro: José. Olympio, 1997, p. 13-32.

TEIXEIRA, Marcos Vinícius. Aníbal Machado: um escritor em preparativos. 2011. Tese (Doutorado em Literatura Brasileira) - Universidade de São Paulo, São Paulo, 2011.

TODOROV, Tzvetan. Introdução à literatura fantástica. Tradução de Maria Clara Correa Castello. 2. ed. São Paulo: Perspectiva, 1992. 